\title{
Tissue-type plasminogen activator is a neuroprotectant in the mouse hippocampus
}

\author{
Ramiro Echeverry, ${ }^{1}$ Jialing Wu,, ${ }^{1,2}$ Woldeab B. Haile, ${ }^{1}$ Johanna Guzman, ${ }^{1}$ and Manuel Yepes ${ }^{1}$ \\ 1Department of Neurology and Center for Neurodegenerative Disease, Emory University School of Medicine, Atlanta, Georgia, USA. \\ ${ }^{2}$ Department of Neurology, Tianjin Huanhu Hospital and Graduate School of Tianjin Medical University, Tianjin, China.
}

\begin{abstract}
The best-known function of the serine protease tissue-type plasminogen activator (tPA) is as a thrombolytic enzyme. However, it is also found in structures of the brain that are highly vulnerable to hypoxia-induced cell death, where its association with neuronal survival is poorly understood. Here, we have demonstrated that hippocampal areas of the mouse brain lacking tPA activity are more vulnerable to neuronal death following an ischemic insult. We found that sublethal hypoxia, which elicits tolerance to subsequent lethal hypoxic/ischemic injury in a natural process known as ischemic preconditioning (IPC), induced a rapid release of neuronal tPA. Treatment of hippocampal neurons with tPA induced tolerance against a lethal hypoxic insult applied either immediately following insult (early IPC) or 24 hours later (delayed IPC). tPA-induced early IPC was independent of the proteolytic activity of tPA and required the engagement of a member of the LDL receptor family. In contrast, tPA-induced delayed IPC required the proteolytic activity of tPA and was mediated by plasmin, the NMDA receptor, and PKB phosphorylation. We also found that IPC in vivo increased tPA activity in the cornu ammonis area 1 (CA1) layer and Akt phosphorylation in the hippocampus, as well as ischemic tolerance in wild-type but not tPA- or plasminogen-deficient mice. These data show that tPA can act as an endogenous neuroprotectant in the murine hippocampus.
\end{abstract}

\section{Introduction}

Tissue-type plasminogen activator $(\mathrm{tPA})$ is a serine proteinase found in the intravascular space and the CNS. In the intravascular space tPA's substrate is plasminogen (1), and its main function is as a thrombolytic enzyme. In the brain tPA is found in the endothelial cell-basement membrane-astrocyte interface, where it modulates cerebrovascular tone (2) and the permeability of the blood-brain barrier $(3,4)$. tPA is also found in neurons, where it has been linked to events associated not only with synaptic plasticity $(5-8)$ but also with cell death $(9,10)$. Accordingly, whereas several studies indicate that tPA mediates excitotoxin-induced cell death (9) and that excess of tPA leads to increased brain injury (10), others have suggested that tPA is neuroprotective (9).

The hippocampus is a brain structure critical for learning, memory, and the development of navigational strategies crucial for survival (11). Anatomically, it can be divided into 4 subregions: cornu ammonis areas 1 (CA1), 2 (CA2), and 3 (CA3) and dentate gyrus (DG). The hippocampus is especially vulnerable to damage caused by a number of injuries including hypoxia/ischemia. Indeed, periods of hypoxia that are not fatal to other brain structures may nonetheless result in significant damage to the hippocampus. However, not all hippocampal areas exhibit the same degree of susceptibility to the ischemic injury, with the CA3 area showing greater resistance to ischemic damage compared with area CA1 (12). Accordingly, a brief period of global brain ischemia causes cell death in hippocampal CA1 pyramidal neurons 48-72 hours after reperfusion, with neuronal preservation in other hippocampal layers. This phenomenon, commonly defined as delayed neuronal death, is also observed in humans after episodes of global hypoperfusion such as following cardiac arrest or systemic hypotension. The hippocam-

Authorship note: Ramiro Echeverry and Jialing Wu contributed equally to this work. Conflict of interest: The authors have declared that no conflict of interest exists. Citation for this article: J Clin Invest. 2010;120(6):2194-2205. doi:10.1172/JCI41722. pus is also one of the areas with the highest levels of tPA activity in the CNS (13). Interestingly, in contrast to the CA2 and CA3 areas, the CA1 layer is devoid of tPA activity (14), suggesting a correlation between the absence of tPA activity and the increased susceptibility to hypoxic/ischemic injury of this hippocampal area.

Preconditioning is a phenomenon whereby exposure to sublethal alterations in the environment results in acquisition of tolerance to otherwise lethal environmental changes. Kitagawa et al. found that induction of sublethal transient global cerebral ischemia (ischemic preconditioning [IPC]) protects neurons in the CA1 hippocampal layer from the deleterious effects of a lethal ischemic insult 24 hours later (15). The induction of this phenomenon, called "ischemic tolerance," is accompanied not by variations in regional tissue perfusion (16), but instead by changes at the cellular level, such as NMDA receptor (NMDAR) activation (17) and Akt phosphorylation (18). Importantly, a growing body of evidence indicates not only the existence of an interaction between TPA and the NMDAR (19-22), but also the induction of Akt phosphorylation by treatment with tPA (18).

In the in vitro and in vivo studies presented here, we demonstrate that tPA deficiency results in increased hippocampal neuronal death following a lethal ischemic injury. Exposure to sublethal hypoxia/ischemia induces a rapid release of tPA from hippocampal neurons in vitro and in vivo, and this event is the first step of a neuroprotective response that leads to neuronal survival. Accordingly, treatment of hippocampal neurons with tPA confers protection against a simultaneous lethal hypoxic insult (early IPC). This protective effect is independent of plasminogen/ plasmin and instead requires the engagement of a member of the $\mathrm{LDL}$ receptor family. Additionally, treatment with tPA also induces tolerance against a lethal insult applied 24 hours later (delayed IPC). This delayed protective effect of tPA requires tPA's proteolytic activity and is mediated by plasmin via NMDAR-dependent Akt phosphorylation. Moreover, our results indicate that endogenous tPA and plasmin mediate the protective effect of delayed precon- 


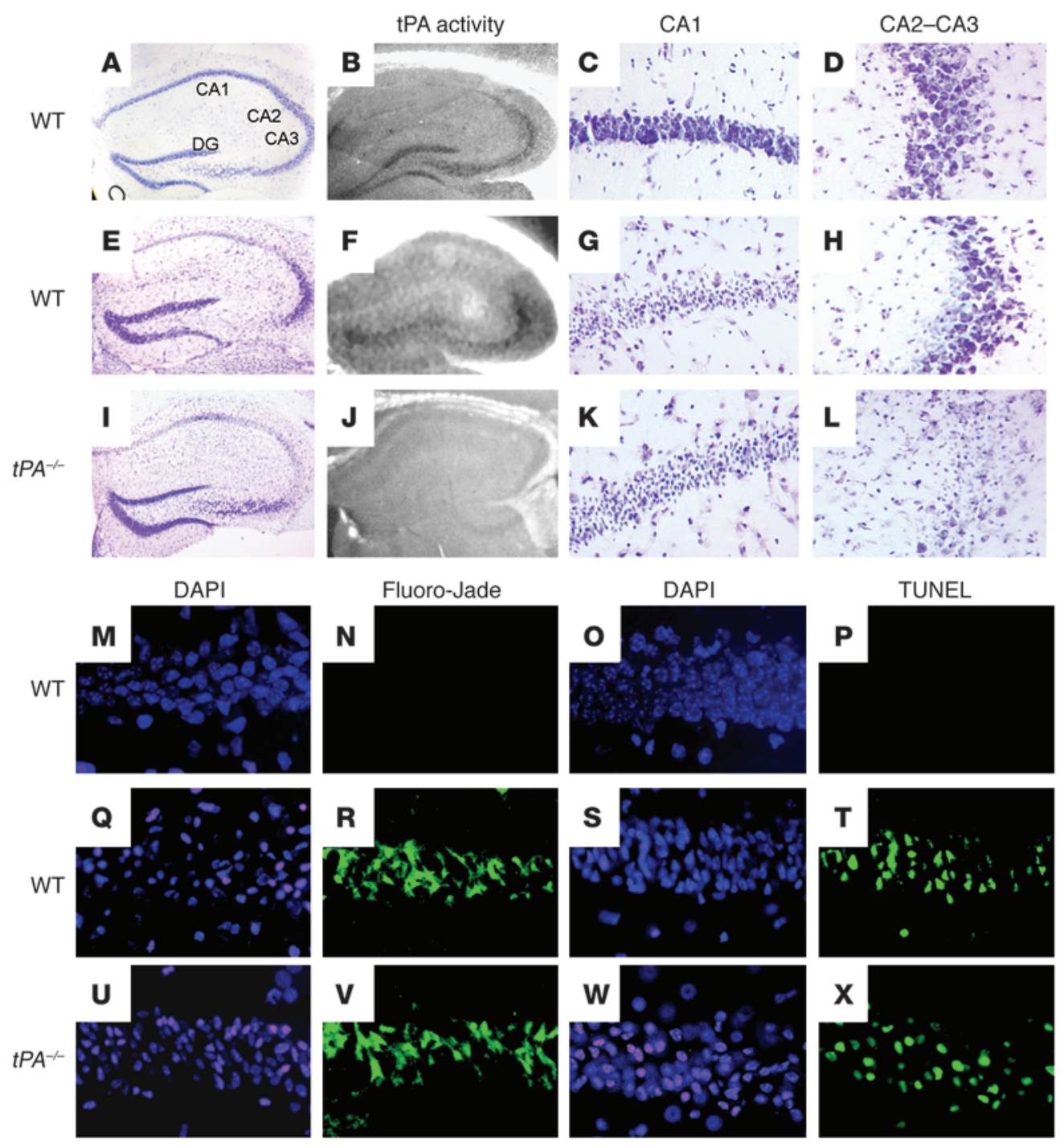

Figure 1

Relationship between tPA activity and hippocampal cell death. (A-L) Representative pictures of cresyl violet staining and in situ zymography assays of the dorsal hippocampus of WT mice under normoxic conditions (A-D) or of WT and tPA-deficient $\left(t P A^{-/-}\right)$mice 72 hours after 20 minutes of BCCAO (E-L). Note the presence of cell death in areas devoid of tPA activity in WT (CA1 layer, G) and $t P A^{-/-}$mice $(C A 1-C A 2$ and CA3 layers; I, K, and L). Original magnification, $\times 4(\mathbf{A}, \mathbf{B}, \mathbf{E}, \mathbf{F}, \mathbf{I}$, and $\mathbf{J})$ and $\times 20(\mathbf{C}, \mathbf{D}, \mathbf{G}, \mathbf{H}, \mathbf{K}$, and $\mathbf{L})$. (M-X) Representative pictures of DAPI, Fluoro-Jade, and TUNEL staining in the CA1 layer of WT mice under normoxic conditions (M-P) or of WT and $t P A^{-/-}$mice 5 days after 20 minutes of BCCAO $(\mathbf{Q}-\mathbf{X})$. Note the presence of widespread necrotic changes, neurodegeneration, and apoptotic cell death in both WT (Q $\mathbf{Q}-\mathbf{T})$ and $t P A^{-/-}$mice $(\mathbf{U}-\mathbf{X})$. Blue is DAPI, and green is Fluoro-Jade $(\mathbf{N}, \mathbf{R}$, and $\mathbf{V})$ or TUNEL $(\mathbf{P}, \mathbf{T}$, and $\mathbf{X})$. Original magnification, $\times 40(\mathbf{M}-\mathbf{X})$.

ditioning induced by exposure to sublethal hypoxia. Together, our data demonstrate that tPA is an endogenous neuroprotectant in the mouse hippocampus.

\section{Results}

Relationship between tPA activity and hippocampal neuronal death. To study the distribution of tPA activity in the normal hippocampus, we performed an in situ zymography assay in hippocampal sections of nonischemic WT mice $(n=4)$. We found that tPA activity was circumscribed to the CA2 and CA3 fields as well as to the DG. In contrast, we did not detect tPA activity in the CA1 layer (Figure 1B). To investigate the effect of hippocampal ischemia on tPA activity, we performed an in situ zymography assay in WT mice following
20 minutes of bilateral common carotid artery occlusion (BCCAO; $n=4)$. We detected tPA's caseinolytic activity in the hippocampal CA2, CA3, and DG fields but failed to observe tPA activity in the CA1 layer (Figure 1F). To correlate our findings with hippocampal neuronal death, we performed cresyl violet staining in a subgroup of WT mice 72 hours after 20 minutes of BCCAO $(n=6)$. We observed that the ischemic insult induced extensive neuronal death in the CA1 layer, with neuronal preservation in the CA2 and CA3 fields (Figure 1, E, G, and H). Then we performed similar experiments in $\mathrm{tPA}^{-/-}$mice $(n=6)$. We found that in contrast to WT mice, in which cell death was limited to the hippocampal CA1 layer, in $t P A^{-/-}$mice there was widespread neuronal death involving not only the CA1 layer, but also the CA2 and CA3 fields (Figure 1, I, K, 

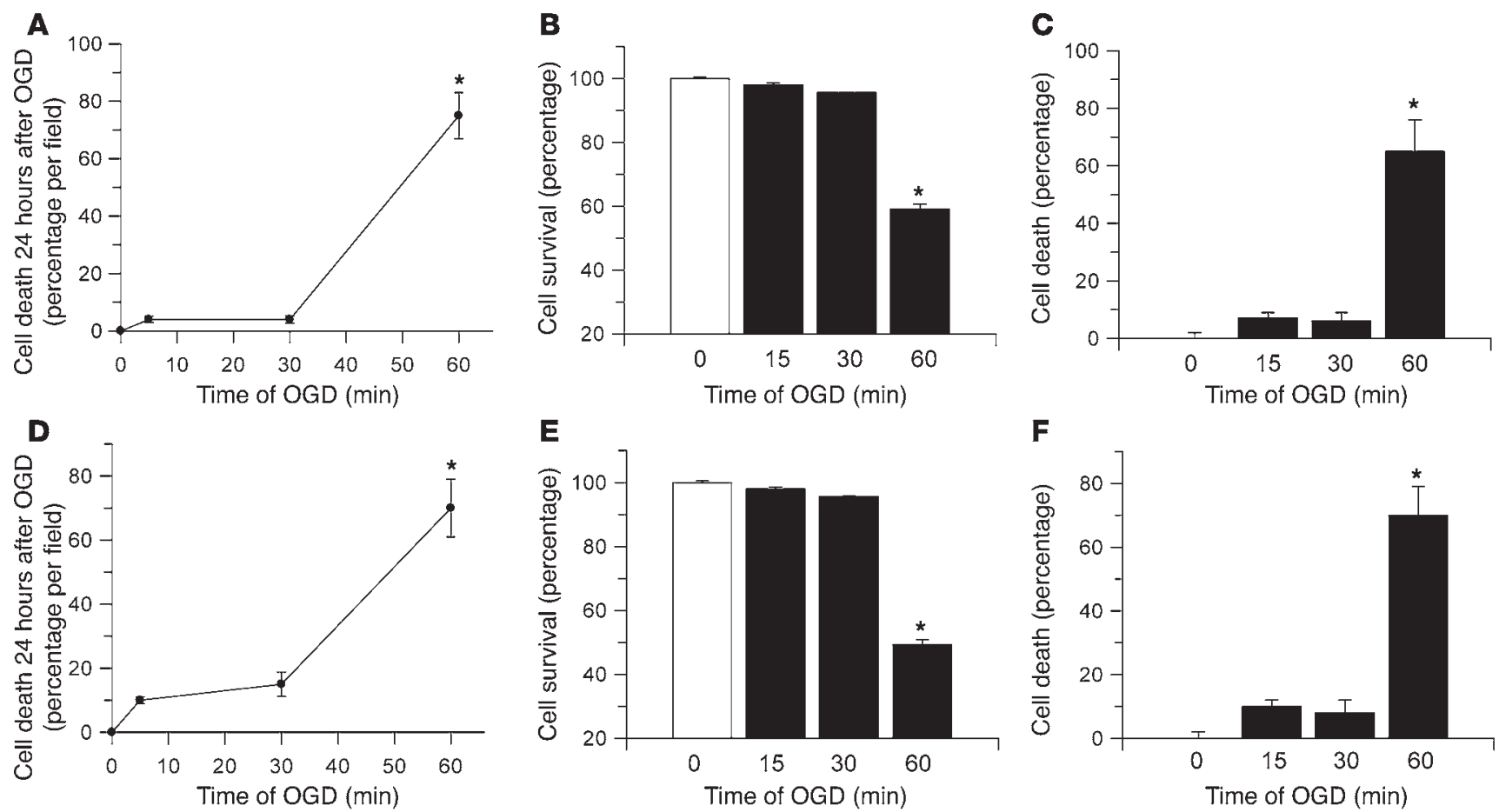

Figure 2

Time-dependent effect of hypoxia on neuronal death. Hippocampal (A-C) and cortical neurons (D-F) were exposed to OGD conditions during $0,15,30$, and 60 minutes, followed by quantification of cell death at each time point by fluorometry (LIVE/DEAD Viability assay; A and $\mathbf{D}$ ) or Trypan blue staining ( $\mathbf{C}$ and $\mathbf{F}$ ) and determination of cell survival with the MTT assay (B and E). Values in $\mathbf{A}, \mathbf{C}, \mathbf{D}$, and $\mathbf{F}$ are given as percentage of dead cells relative to the total number of cells per field. Values in $\mathbf{B}$ and $\mathbf{E}$ are given as percentage compared with cell survival in neurons maintained under normoxic conditions. Error bars denote SD. ${ }^{\star} P<0.05$ compared with cells maintained under OGD for 0-30 minutes. $n=6-12$ observations for each experiment.

and L). Because delayed neuronal death may occur as late as 5 days after BCCAO (15), and to better understand the mechanisms of cell death involved in this process, we performed DAPI, Fluoro-Jade, and TUNEL staining in the hippocampus of WT and $t P A^{-/-}$mice 5 days after 20 minutes of BCCAO $(n=6)$. Our DAPI staining indicated the presence of widespread necrotic changes in both WT and $t P A^{-/-}$mice that corresponded to areas of neurodegeneration (Figure $1, \mathrm{Q}, \mathrm{R}, \mathrm{U}$, and $\mathrm{V}$ ). We also detected extensive zones of apoptotic cell death in both strains of mice (Figure 1, T and $\mathrm{X}$ ).

Effect of hypoxia on neuronal cell death. The effect of hypoxia on neuronal death varies not only with the severity but also with the duration of the hypoxic insult. Indeed, there is a sublethal period of time during which exposure to hypoxia/ischemia does not induce cell death but instead may activate neuroprotective mechanisms (17). To characterize this effect, hippocampal and cortical neurons were exposed to 0-60 minutes of oxygen-glucose deprivation (OGD) conditions, followed by determination of cell death/survival by 3 different methods: a fluorescence assay that differentially detects dead and live cells; the 3-(4,5-dimethylthiazol-2-yl)-2,5-diphenyltetrazolium bromide (MTT) assay, which detects cell survival; and Trypan blue staining, which differentiates viable from nonviable cells. Our results indicate that exposure to 0-30 minutes of OGD does not cause significant cell death or changes in neuronal survival. In contrast, exposure to 60 minutes of OGD increased cell death in hippocampal neurons to $75 \% \pm 8 \%$ (by the fluorescence assay) and $65 \% \pm 11 \%$ (by the Trypan blue method), with a reduction in neuronal survival to $57 \% \pm 7.9 \%$ (by MTT assay). Likewise, cortical neuronal death increased at 60 minutes to $70 \% \pm 9 \%$ and $65 \% \pm 8 \%$ (fluorescence assay and Trypan blue methods, respectively), with a reduction in neuronal survival to $49.3 \% \pm 1.5 \%$ (MTT assay; Figure 2).

Effect of hypoxia on the release of neuronal $t P A$. To investigate the effect of OGD conditions on the release of neuronal tPA, hippocampal and cortical neurons were exposed to OGD conditions for 0-60 minutes, followed by quantification of the release of tPA into the media with an ELISA. We found that OGD conditions induced a rapid release of tPA from both hippocampal and cortical neurons the first minute after the onset of the hypoxic insult (Figure 3, A and D).

Effect of tPA on neuronal survival. To study the effect of tPA on neuronal survival, hippocampal and cortical neurons were incubated under normoxic conditions with progressive concentrations of tPA $(0-1 \mu \mathrm{M})$, followed by determination of cell survival 24 hours later with the MTT assay. We found that incubation with tPA did not induce cell death in hippocampal neurons (Figure 3B). In contrast, $100 \mathrm{nM}, 500 \mathrm{nM}$, and $1 \mu \mathrm{M}$ tPA decreased cortical neuronal survival to $91 \% \pm 0.1 \%, 92 \% \pm 0.13 \%$, and $96 \% \pm 0.1 \%$, respectively (Figure 3E). To investigate whether endogenous $\mathrm{tPA}$, released from neurons in response to OGD exposure, has an effect on cell survival, WT and $t P A^{-/-}$hippocampal and cortical neurons were exposed to OGD conditions for 55 minutes, followed 24 hours later by determination of cell survival $(n=10)$. A subset of cells was incubated with recombinant $\mathrm{PPA}$ simultaneously with the hypoxic insult (Figure 3, C and F). Our results indicate that 55 minutes of OGD decreased neuronal survival in WT and $t P A^{-/-}$hippocampal neurons to $55.7 \% \pm 2.9 \%$ and $53.3 \% \pm 5.8 \%$, respectively. Surprisingly, 
A
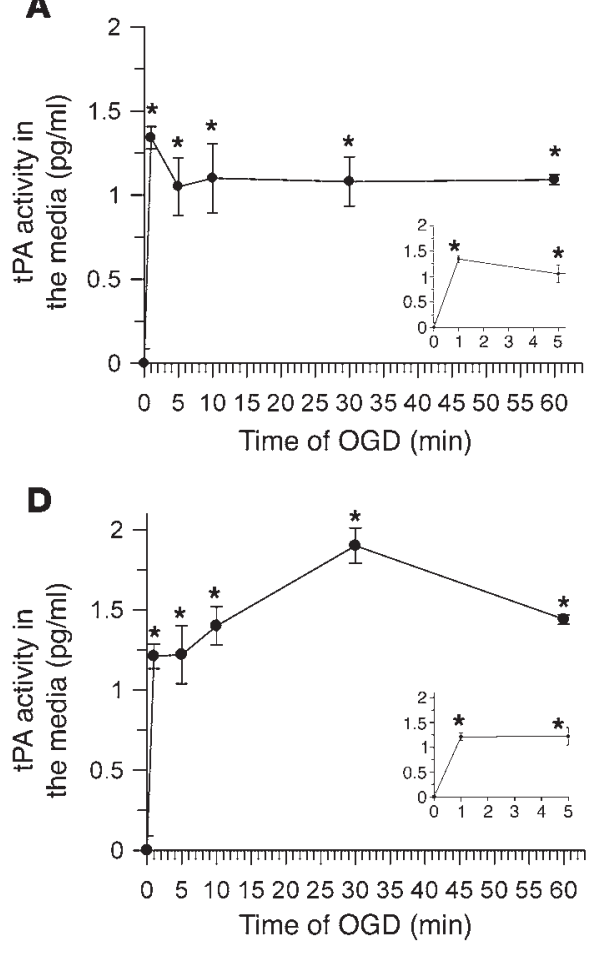

B
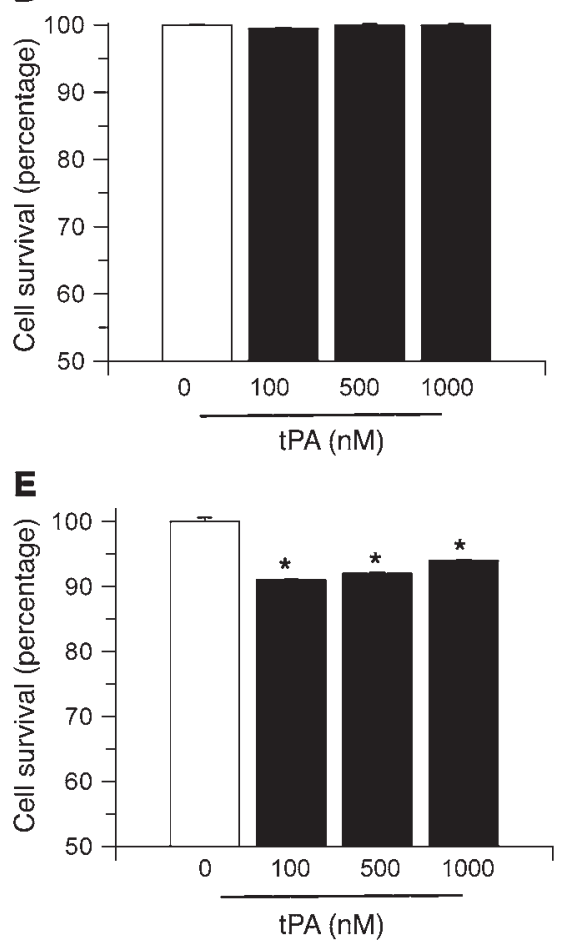
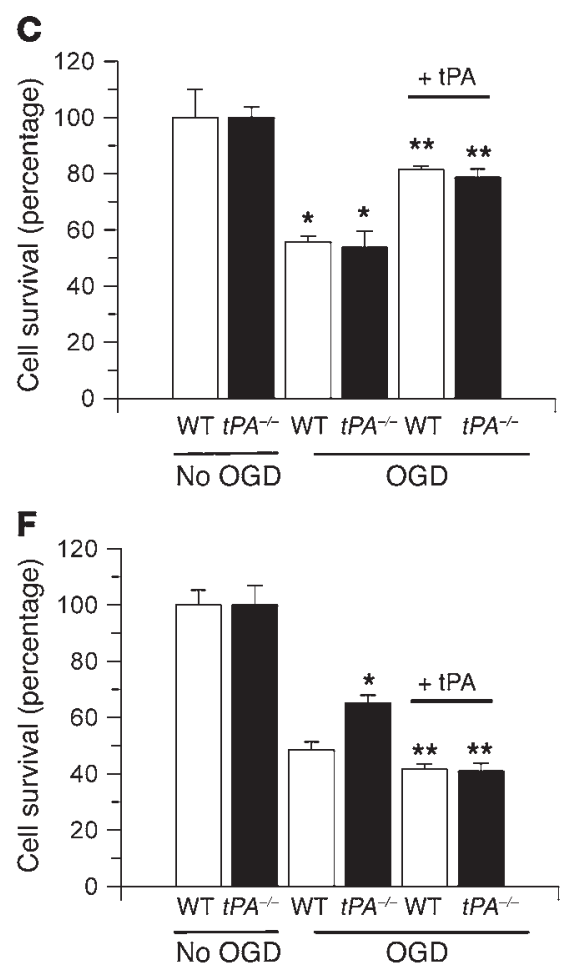

\section{Figure 3}

Effect of tPA on neuronal survival. (A and D) Mean increase in enzymatically active tPA in the media of hippocampal (A) and cortical (D) neurons exposed to OGD conditions for 0-60 minutes. Error bars denote SD. $n=12$. ${ }^{*} P<0.05$ compared with controls maintained under normoxia. The insets are magnifications of the first 5 minutes of each curve. (B and $\mathbf{E})$ Mean reduction in cell survival in hippocampal (B) and cortical neurons (E) 24 hours after incubation with 0-1 $\mathrm{MM}$ tPA under normoxic conditions. Error bars denote SD. $n=10 .{ }^{*} P<0.05$ compared with untreated cells (white bar). (C and F) Mean decrease in cell survival in WT (white bars) and tPA deficient (tPA-/-; black bars) hippocampal (C) and cortical (F) neurons exposed to 55 minutes of OGD conditions or kept under normoxic conditions (no OGD). A subgroup of neurons was incubated with $1 \mu \mathrm{M}$ tPA (+ tPA). Error bars denote SD. $n=10$ for each observation. In C: ${ }^{*} P<0.05$ compared with cells kept under normoxic conditions; ${ }^{\star \star} P<0.05$ compared with neurons maintained under OGD conditions without tPA. In F: ${ }^{\star} P<0.05$ compared with WT cells maintained under OGD conditions without tPA or with WT and $t P A^{-/-}$neurons maintained under OGD conditions and treated with $\mathrm{tPA} ;{ }^{* *} P<0.05$ compared with WT and $t P A^{-/-}$neurons maintained under OGD conditions without tPA.

we found that incubation with tPA increased cell survival in WT and $t P A^{-/-}$hippocampal neurons to $81.4 \% \pm 1.2 \%$ and $78.65 \% \pm 3 \%$, respectively (Figure $3 \mathrm{C}$ ). We also found that OGD decreased cell survival in WT cortical neurons to $48.44 \% \pm 2.8 \%$. However, in contrast to hippocampal neurons, this effect was attenuated in $t P A^{-/-}$ cortical neurons $(65 \% \pm 2.8 \%)$. Also in contrast to our observations in hippocampal neurons, incubation with tPA decreased neuronal cortical survival in both WT and $t P A^{-/-}$cultures to $41.59 \% \pm 1.88 \%$ and $40.9 \% \pm 2.7 \%$, respectively (Figure $3 \mathrm{~F}$ ).

Neuroprotective effect of $t P A$ on early preconditioning. There are two types of IPC: early and delayed (15). In early preconditioning, treatment with the protective agent simultaneously or very close to the exposure to the lethal insult promotes cell survival. In contrast, in delayed preconditioning, the development of tolerance is induced by treatment with the protective agent 24 hours before exposure to the lethal injury. Our results indicate that although endogenous tPA does not have an effect on early preconditioning, treatment with recombinant tPA during OGD increases hippocampal neuronal survival (Figure 3C). To study the effect of recombinant tPA on early preconditioning, we determined cell survival in WT hippocampal neurons incubated with 0-1 $\mu \mathrm{M}$ tPA followed by exposure to OGD conditions for 55 minutes. We found that whereas $60 \mathrm{nM}$ and $100 \mathrm{nM}$ tPA did not have an effect on cell survival, incubation with $500 \mathrm{nM}$ and $1 \mu \mathrm{M}$ tPA increased neuronal survival from $55.71 \% \pm 1.9 \%$ (in cells not incubated with tPA) to $73.6 \% \pm 6.4 \%$ and $81.4 \% \pm 0.9 \%$, respectively (Figure $4 \mathrm{~A}$ ). To study whether the proteolytic action of $\mathrm{tPA}$ is needed for this protective effect, we performed similar experiments with proteolytically inactive tPA (itPA). We found that incubation with itPA also increased hippocampal neuronal survival, to $86.02 \% \pm 1.55 \%$ (Figure $4 \mathrm{~A}$ ). To further study this effect, a subgroup of neurons was incubated with a combination of tPA and $\alpha_{2}$-antiplasmin $(140 \mathrm{nM})$ or with plasmin alone $(100 \mathrm{nM})$. We found not only that $\alpha_{2}$-antiplasmin did not abrogate the protective effect of tPA, but also that incubation with plasmin alone failed to induce neuronal survival (Figure 4B). Because a growing body of evidence has demonstrated that in the brain some effects of tPA are not mediated by plasminogen/plasmin but instead by the LDL receptor-related protein-1 (LRP1; refs. $3,4,23,24)$, we performed similar experiments in hippocampal neurons incubated with either tPA alone or with a combination of tPA and the receptor-associated protein (RAP, $100 \mathrm{nM}$ ), a universal inhibitor of members of the LDL receptor family. Our results indicate that cotreatment with RAP abrogates the protective effect of tPA on early preconditioning (Figure 4B). 
A PREC.

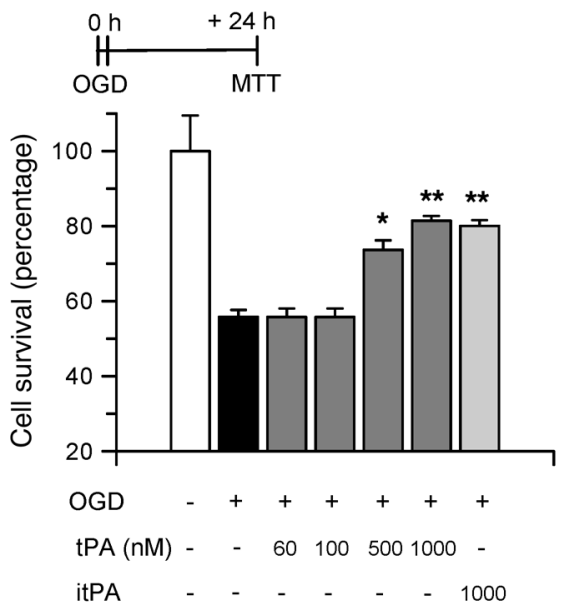

C PREC

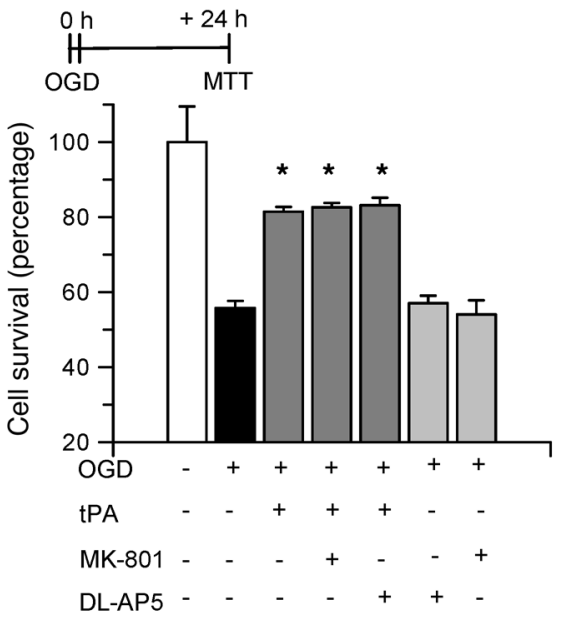

B
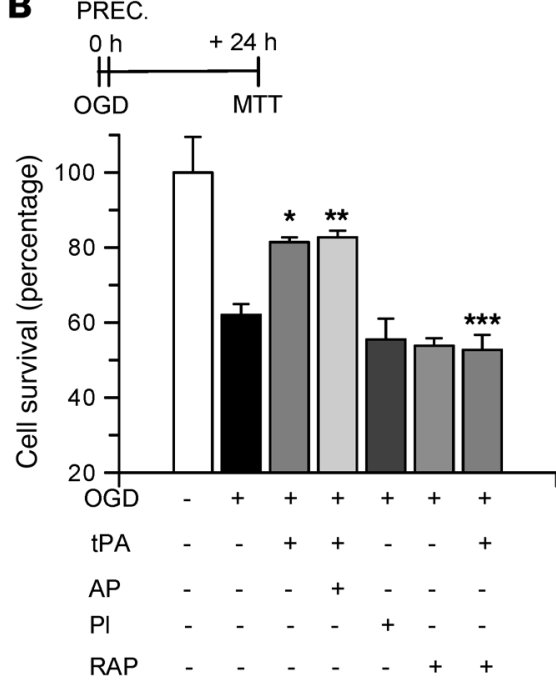

D tPA
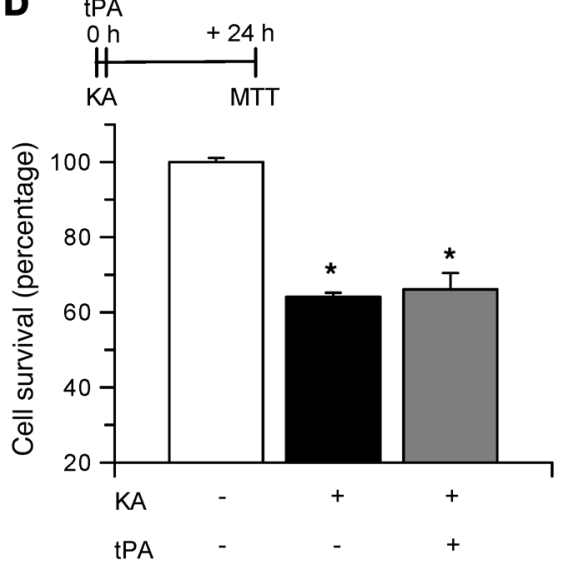

Figure 4

tPA-induced early preconditioning. (A) Mean cell survival in hippocampal neurons treated with either IPA (in nM) or with itPA followed by exposure to OGD conditions during 55 minutes. $n=20$ for each observation. Error bars denote SD. ${ }^{*} P<0.05$ compared with untreated cells; ${ }^{\star \star} P<0.05$ compared with untreated neurons and with cells treated with $500 \mathrm{nM}$ tPA. (B and C) Mean hippocampal neuronal survival following exposure to OGD conditions (55 minutes) and incubation with $1 \mu \mathrm{M}$ tPA alone or in combination with either $\alpha_{2}$-antiplasmin (AP, $\left.140 \mathrm{nM}\right)$ or RAP (100 nM) or with either one of the NMDAR antagonists MK-801 $(10 \mu \mathrm{M})$ or DL-AP5 $(50 \mu \mathrm{M})$ or with plasmin alone (PI; $100 \mathrm{nM}$ ) or with RAP alone. $n=20$ in $\mathbf{B}$ and $n=15$ in C. Error bars denote SD. In $\mathbf{B}:{ }^{*} P<0.05$ compared with cells left untreated; ${ }^{*} P<0.05$ compared with cells kept under OGD conditions; ${ }^{* * *} P<0.05$ compared with neurons maintained under OGD conditions and with TPA alone. In C: ${ }^{*} P<0.05$ compared with cells maintained under OGD conditions and either left untreated or incubated with MK-801 or DL-AP5 alone. (D) Mean neuronal survival following incubation with $250 \mu \mathrm{M} \mathrm{KA}$ either alone or in combination with $1 \mu \mathrm{M}$ tPA. ${ }^{*} P<0.05 \mathrm{com}$ pared with untreated cells. $n=10$. Error bars denote SD in all panels. "PREC." (preconditioning) indicates the moment when cells were incubated with each compound.
Effect of NMDAR antagonism on $\mathrm{PPA}$-induced early preconditioning. It has been demonstrated that NMDAR activation mediates the protective effect of delayed preconditioning (17). Likewise, a growing body of evidence indicates the existence of an interaction between IPA and the NMDAR $(20,22,25)$. Then we investigated whether the NMDAR mediates the early neuroprotective effect of tPA. As shown in Figure 4C, cotreatment with 2 different NMDAR antagonists $(10 \mu \mathrm{M}$ MK-801 or $50 \mu \mathrm{M}$ DL-AP5) did not inhibit the protective effect of tPA (Figure 4C). These findings indicate that the protective effect of tPA in early preconditioning is not associated with attenuation of the excitotoxic injury induced by the hypoxic insult. To further test this hypothesis, we studied neuronal survival in WT hippocampal neurons incubated with kainic acid (KA, $250 \mu \mathrm{M})$ either alone or in combination with $1 \mu \mathrm{M}$ tPA. Our results indicate that incubation with $\mathrm{KA}$ alone decreases neuronal survival to $64.1 \% \pm 1.1 \%$ and that this effect is not attenuated by cotreatment with $\mathrm{tPA}(66.04 \% \pm 4.4 \%$; Figure $4 \mathrm{D})$, indicating that the protective effect of tPA in early preconditioning is not mediated by attenuation of the excitotoxic injury.

Effect of $t P A$ on delayed preconditioning. We then investigated whether tPA was also protective in a model of delayed preconditioning. WT hippocampal neurons were incubated with $0-1 \mu \mathrm{M}$ tPA followed 24 hours later by exposure to 55 minutes of OGD conditions and determination of neuronal survival. We found that incubation with $60 \mathrm{nM}$
tPA increased neuronal survival from $62 \% \pm 2.88 \%$ to $88.28 \% \pm 2.72 \%$ and that this effect required tPA's proteolytic activity (Figure $5 \mathrm{~A}$ ). Then we decided to investigate whether this delayed protective effect of tPA is mediated by the plasminogen/plasmin system. WT hippocampal neurons were incubated with $60 \mathrm{nM}$ tPA alone; with a combination of tPA and $140 \mathrm{nM} \alpha_{2}$-antiplasmin, $1.4 \mu \mathrm{M}$ aprotinin, $20 \mathrm{mM} \varepsilon$-aminocaproic acid (EACA), or $100 \mathrm{nM}$ RAP; with plasmin alone $(100 \mathrm{nM})$; or with plasminogen alone $(200 \mathrm{nM})$, 24 hours before exposure to lethal OGD conditions. As shown in Figure $5 \mathrm{~B}$, the protective effect of $\mathrm{TPA}$ was inhibited by coincubation with $\alpha_{2}$-antiplasmin, aprotinin, or EACA, and consistent with this finding, incubation with plasmin alone increased neuronal survival to $86.44 \% \pm 1.64 \%$, an effect comparable to that observed following incubation with tPA alone (87.94\% $\pm 1.39 \%$; Figure $5 B)$. Importantly, treatment with plasminogen alone did not have a protective effect $(60.03 \% \pm 1.58 \%)$. To study whether the LDL receptor plays a role on $\mathrm{tPA}$-induced delayed preconditioning, we performed similar experiments following incubation with either tPA alone or in combination with RAP. In contrast to tPA-induced early preconditioning, we found that whereas treatment with $\mathrm{tPA}$ alone increased neuronal survival from $57.3 \% \pm 1.7 \%$ to $82.93 \% \pm 1.3 \%$, cotreatment with a combination of $\mathrm{tPA}$ and RAP further increased this protective effect to $93.8 \% \pm 2.6 \%$ (Figure $5 B$ ). Treatment with $\alpha_{2}$-antiplas- 
A
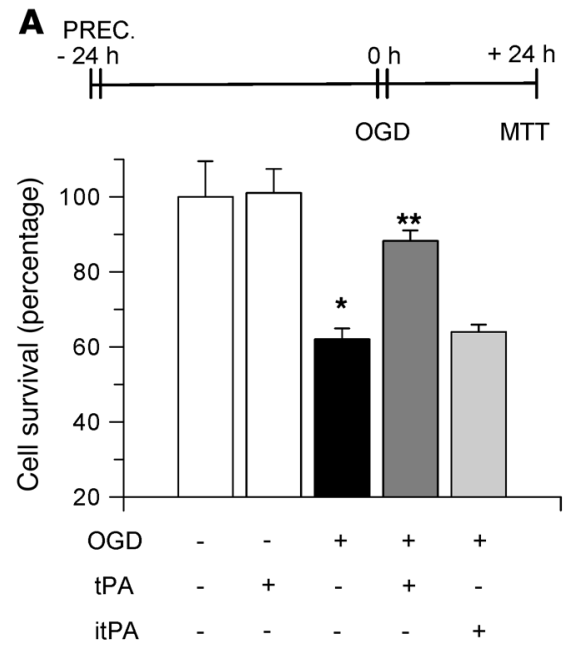

D
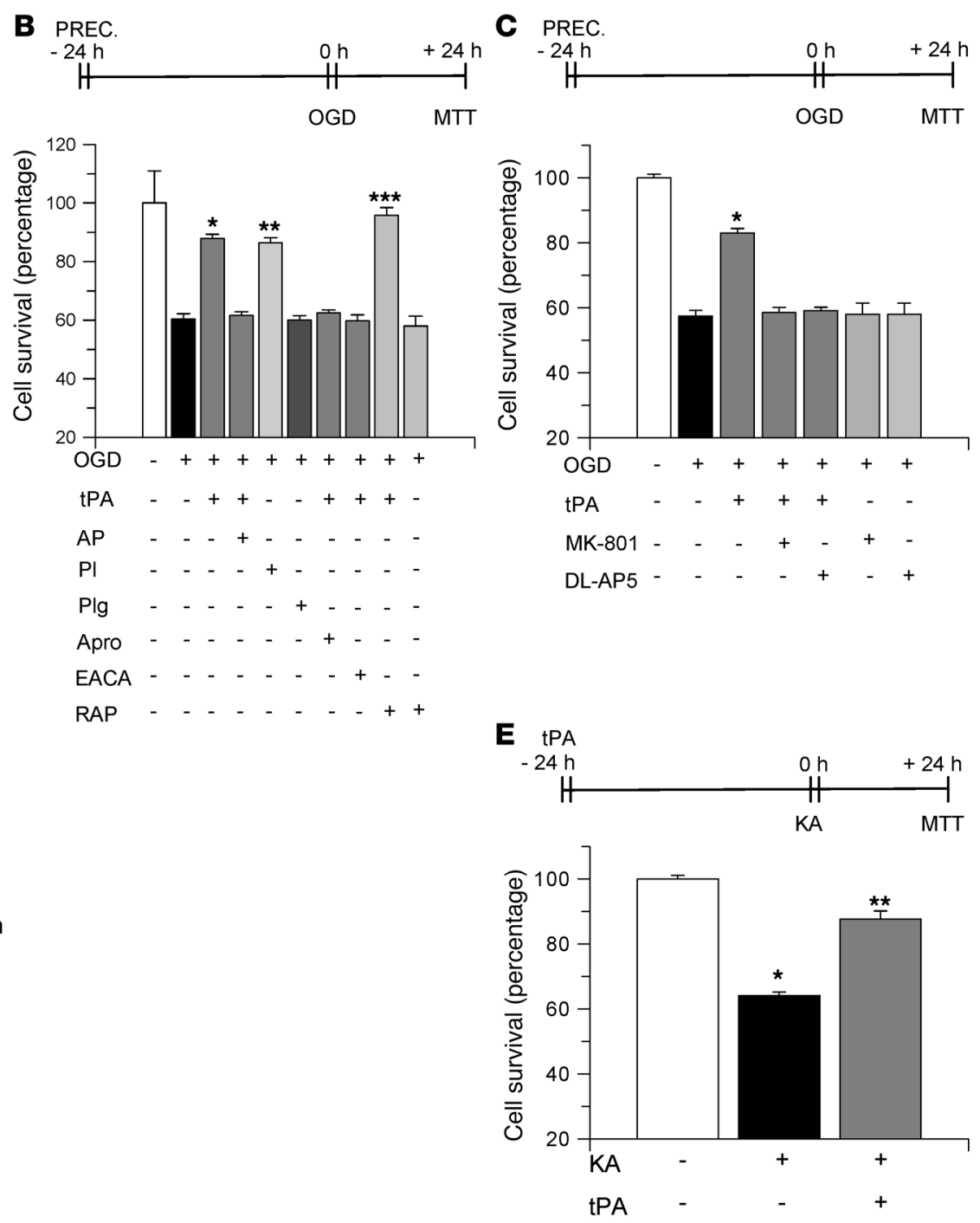

Figure 5

tPA-induced delayed preconditioning. (A-C) Mean survival in hippocampal neurons exposed to OGD conditions (55 minutes) 24 hours after treatment with $60 \mathrm{nM}$ tPA or $1 \mu \mathrm{M}$ itPA (A); or with a combination of $60 \mathrm{nM}$ tPA and $140 \mathrm{nM} \alpha_{2}$-antiplasmin, $1.4 \mu \mathrm{M}$ aprotinin (Apro), $20 \mathrm{mM}$ EACA, $100 \mathrm{nM}$ RAP, $10 \mu \mathrm{M}$ MK-801, or $50 \mu \mathrm{M}$ DL-AP5; or with $200 \mathrm{nM}$ plasminogen (Plg) alone or $100 \mathrm{nM}$ plasmin alone or RAP alone (B and C). In A: ${ }^{\star} P<0.05$ compared with cells under normoxic conditions; ${ }^{* *} P<0.05$ compared with untreated neurons under OGD conditions and with cells treated with itPA. In B and C: ${ }^{*} P<0.05$ compared with untreated cells under OGD conditions; ${ }^{* \star} P<0.05$ compared with untreated cells; ${ }^{* \star *} P<0.05$ compared with cells treated with tPA or plasmin alone. $n=20$ for each observation in A and $\mathbf{B}$ and $n=15$ in C. Error bars denote SD. (D) Western blot analysis detecting the expression of the NR2A subunit of the NMDAR in hippocampal neurons incubated with $60 \mathrm{nM} \mathrm{tPA}$ or $100 \mathrm{nM}$ plasmin. (E) Mean neuronal survival following incubation with $250 \mu \mathrm{M} \mathrm{KA}$ alone or 24 hours after treatment with $60 \mathrm{nM}$ tPA. ${ }^{*} P<0.05$ compared with untreated cells; ${ }^{\star \star} P<0.05$ compared with KA-treated cells. $n=10$. Error bars denote SD in all panels.

min alone, aprotinin alone, EACA alone (data not shown), or RAP alone did not have an effect on delayed preconditioning.

Effect of NMDAR antagonism on $\mathrm{PPA}$-induced delayed preconditioning. Then we investigated whether the NMDAR mediates the neuroprotective effect of tPA in the same model of delayed preconditioning. As shown in Figure 5C, in contrast to our observation in the model of early preconditioning, cotreatment with either MK-801 or DL-AP5 completely blocked the protective effect of tPA $(58.49 \% \pm 1.59 \%$ and $59.12 \% \pm 1.99 \%$ cell survival, respectively; Figure 5C). Importantly, incubation with neither of these NMDAR antagonists alone induced delayed preconditioning. It has been reported that the NR2A subunit of the NMDAR mediates the pro- tective effect of IPC in the hippocampus $(26,27)$. Likewise, in earlier studies we found that plasmin cleaves the NR2A subunit of the NMDAR in hippocampal neurons, relieving the inhibition of this receptor by zinc (28). Thus, we decided to study the effect of tPA on the cleavage of the NR2A subunit in hippocampal neurons left untreated or incubated with either $60 \mathrm{nM}$ tPA or $100 \mathrm{nM}$ plasmin. Our results indicate that incubation with either tPA or plasmin decreases the expression of the NR2A subunit in cell lysates, with the detection of approximately $80 \mathrm{kDa}$ cleavage product in the culture medium (Figure 5D). Together, our observations indicate that the delayed protective effect of tPA is mediated by attenuation of the excitotoxic injury. To test this hypothesis, we studied neuronal 
A

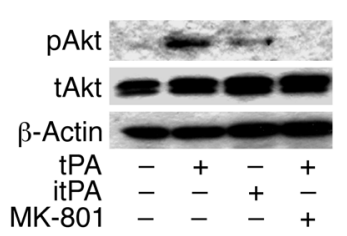

B PREC

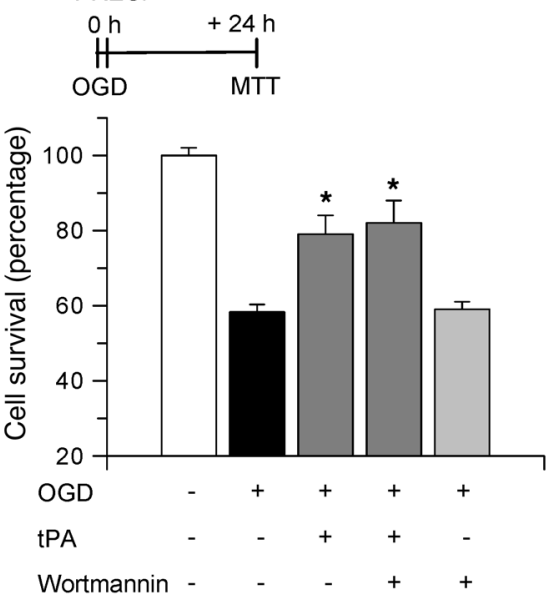

C
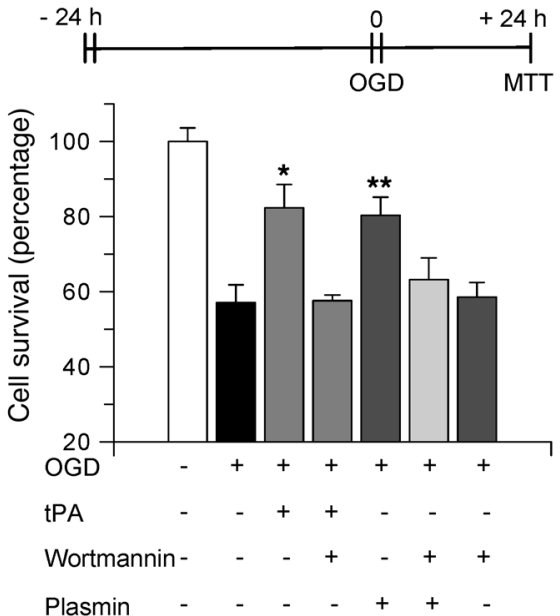

Figure 6

Akt phosphorylation mediates tPA-induced delayed tolerance. (A) Representative image of Western blot analysis for Akt phosphorylated at serine 473 (pAkt), total Akt (tAkt), and $\beta$-actin in lysates from WT hippocampal neurons incubated during 60 minutes with 60 nM tPA, 60 nM itPA, or a combination of tPA and $10 \mu \mathrm{M}$ MK-801. (B) Mean MTT reduction in hippocampal neurons incubated with tPA either alone or in combination with wortmannin $20 \mathrm{nM}$ while exposed to OGD conditions for 55 minutes. $n=10$. Error bars denote SD. ${ }^{\star} P<0.05$ compared with other experimental groups. (C) Mean MTT reduction in hippocampal neurons incubated with $60 \mathrm{nM}$ tPA, $100 \mathrm{nM}$ plasmin, or $20 \mathrm{nM}$ wortmannin or with a combination of tPA and wortmannin or wortmannin and plasmin, followed 24 hours later by exposure to OGD conditions for 55 minutes. $n=12$. Lines denote SD. ${ }^{\star} P<0.05$ compared with neurons treated with a combination of wortmannin and tPA; ${ }^{* *} P<0.05$ compared with neurons treated with a combination of wortmannin and plasmin. "PREC." denotes the moment of incubation with each compound. MTT, quantification of cell survival by MTT assay.

survival in WT hippocampal neurons treated with $60 \mathrm{nM}$ tPA followed 24 hours later by incubation with $250 \mu \mathrm{M}$ KA. In contrast to our observations in early preconditioning, we found that incubation with tPA 24 hours before the excitotoxic injury with KA increased neuronal survival from $64.1 \% \pm 1.3 \%$ to $87.6 \% \pm 2.5 \%$ (Figure $5 \mathrm{E}$ ).

Akt phosphorylation mediates tPA-induced delayed IPC. Because a large body of evidence indicates that during cerebral ischemia Akt phosphorylation induces neuronal survival (18), we decided to investigate whether Akt mediates the protective effect of tPA. First, we performed a Western blot analysis for Akt phosphorylated at serine 473 (pAkt) in cell lysates of hippocampal neurons untreated or incubated under normoxic conditions for 60 minutes with $60 \mathrm{nM}$ active tPA, $60 \mathrm{nM}$ itPA, or a combination of active $\mathrm{tPA}$ and $10 \mu \mathrm{M} \mathrm{MK}-801$. As shown in Figure $6 \mathrm{~A}$, incubation with proteolytically active $\mathrm{PA}$ induced a rapid increase in pAkt expression. In contrast, this effect was abrogated by cotreatment with the NMDAR antagonist MK-801 and was not observed following treatment with itPA. Then we studied whether this rapid phosphorylation of Akt mediates the effect of tPA on early IPC. WT hippocampal neurons were incubated with tPA alone, tPA in combination with $20 \mathrm{nM}$ wortmannin, or wortmannin alone and exposed to lethal OGD conditions (55 minutes). Our results indicate that wortmannin did not abrogate the immediate protective effect of incubation with tPA (Figure 6B), indicating that Akt phosphorylation does not mediate the effect of $\mathrm{tPA}$ on early preconditioning. Then we decided to study whether phosphorylation of Akt mediates the protective effect of tPA on a model of delayed preconditioning. WT hippocampal neurons were incubated with tPA alone, plasmin alone, or wortmannin alone or with a combination of $\mathrm{tPA}$ and wortmannin or plasmin and wortmannin, followed 24 hours later by exposure to OGD conditions for 55 minutes. We found that in contrast to immediate preconditioning, cotreatment with wortmannin significantly attenuated the delayed protective effect of tPA on cell survival, from
$86.1 \% \pm 6.5 \%$ in neurons incubated with tPA alone to $60.5 \% \pm 5.5 \%$ in cells treated with a combination of tPA and wortmannin. Additionally, incubation with plasmin alone increased cell survival to $86 \% \pm 8 \%$ and this effect was abrogated by cotreatment with wortmannin (Figure 6C). Importantly, incubation with wortmannin alone did not have an effect on delayed preconditioning.

Effect of endogenous tPA on delayed bypoxic preconditioning. Because our results indicate that low concentrations of recombinant $\mathrm{tPA}(60 \mathrm{nM})$ induce delayed tolerance, we hypothesized that endogenous tPA, released in response to the hypoxic insult, also may induce delayed IPC. To test this hypothesis, we used a previously validated model of hypoxic preconditioning where exposure to sublethal hypoxia (30 minutes OGD) confers protection against the deleterious effects of lethal hypoxia (55 minutes OGD) 24 hours later (17). WT and $t P A^{-/-}$neurons were exposed to sublethal OGD conditions (preconditioning event), followed 24 hours later by exposure to lethal OGD conditions (55 minutes) and determination of cell survival. A subgroup of cells was incubated under OGD conditions for 55 minutes without previous preconditioning. As shown in Figure 7A, survival of WT hippocampal neurons after 55 minutes of OGD increased from $58.10 \% \pm 2.3 \%$ in non-preconditioned cells to $80 \% \pm 0.9 \%$ in preconditioned neurons. In contrast, survival of $t \mathrm{PA}^{-/-}$neurons after 55 minutes of incubation under OGD conditions remained unchanged despite hypoxic preconditioning $(60.3 \% \pm 1.2 \%$ and $60.77 \% \pm 2.3 \%$, respectively). To see whether this protective effect of endogenous tPA was mediated by plasminogen/plasmin, WT neurons were preconditioned with 30 minutes of OGD either alone or in the presence of $140 \mathrm{nM}$ $\alpha_{2}$-antiplasmin, $1.4 \mu \mathrm{M}$ aprotinin, or $20 \mathrm{mM}$ EACA, followed 24 hours later by exposure to lethal OGD conditions. Our results indicate that incubation with either one of these plasminogen/plasmin inhibitors completely abolished the effect of IPC (Figure 7B). Then we performed similar observations in WT neurons incubated with MK-801 or wort- 
A

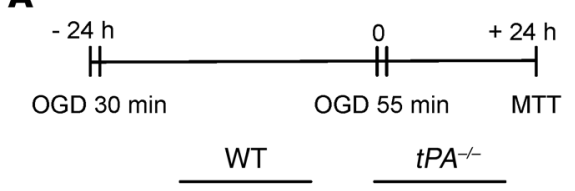

B
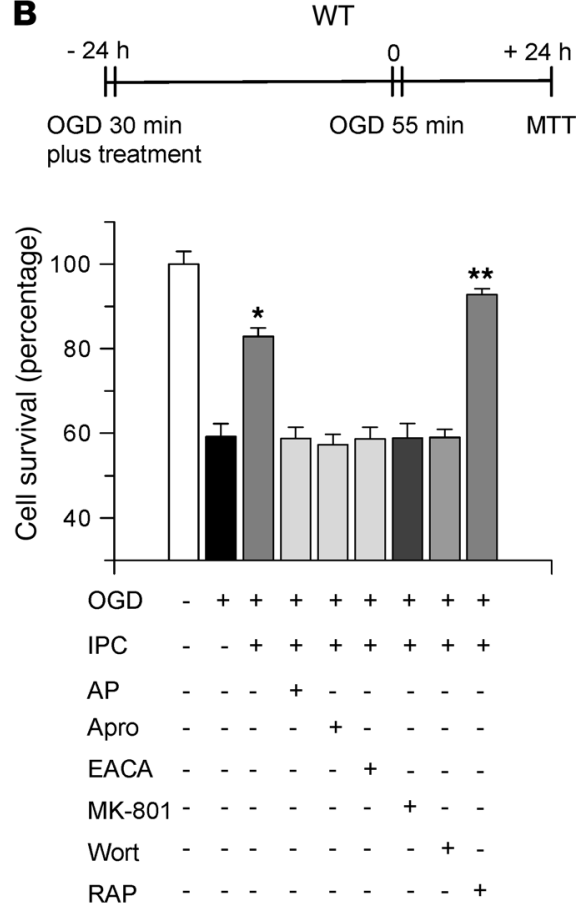

C
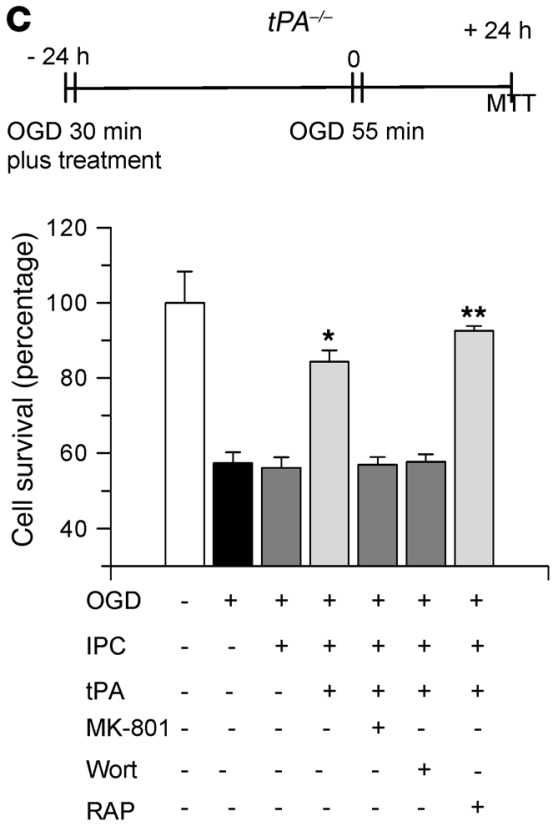

Figure 7

Endogenous tPA induces delayed hypoxic preconditioning. (A) Mean neuronal survival in WT and $t P A^{-/-}$neurons preconditioned with sublethal OGD conditions for 30 minutes, followed 24 hours later by exposure to lethal OGD (55 minutes). $n=12-15$. ${ }^{\star} P<0.05$ compared with WT neurons maintained under normoxic conditions; ${ }^{* *} P<0.05$ compared with non-preconditioned neurons; ${ }^{* \star} P<0.05$ compared with $t P A{ }^{-/-}$ cells maintained under normoxia. (B) Mean neuronal survival in WT neurons preconditioned with sublethal OGD in the presence of 140 nM $\alpha_{2}$-antiplasmin, $1.4 \mu \mathrm{M}$ aprotinin, $20 \mathrm{mM}$ EACA, $10 \mu \mathrm{M}$ MK-801, $20 \mathrm{nM}$ wortmannin (Wort), or $100 \mathrm{nM}$ RAP. $n=6-10$. * $P<0.05$ compared with non-preconditioned cells; ${ }^{* *} P<0.05$ compared with all preconditioned cells. (C) Mean neuronal survival in $t P A^{-/-}$neurons preconditioned with sublethal OGD in the presence of $60 \mathrm{nM}$ tPA or with a combination of tPA and $10 \mu \mathrm{M} \mathrm{MK}-801$, tPA and 20 nM wortmannin, or tPA and 100 nM RAP, followed 24 hours by a lethal hypoxic injury (55 minutes of OGD). Error bars denote $\mathrm{SD}$. $n=8-10$. ${ }^{\star} P<0.05$ compared with untreated preconditioned cells; ${ }^{*} P<0.05$ compared with cells preconditioned in the presence of tPA.

mannin during the preconditioning phase. We found that antagonism of the NMDAR or inhibition of Akt phosphorylation completely abrogated the protective effect of the preconditioning event (Figure 7B). Importantly, we observed that incubation with $100 \mathrm{nM}$ RAP during the preconditioning phase increased the protective effect of IPC from $56.19 \% \pm 3.03 \%$ in non-preconditioned cells, to $82.85 \% \pm 2.045 \%$ in WT cells preconditioned with sublethal ischemia without RAP and to $92.77 \% \pm 1.41 \%$ in cells preconditioned with a sublethal hypoxic injury in the presence of RAP. To further characterize our observations, we performed similar experiments with $t \mathrm{PA}^{-/-}$ hippocampal neurons. A subgroup of neurons was incubated during the preconditioning phase with $\mathrm{PPA} 60 \mathrm{nM}$, or with a combination of tPA and MK-801, tPA and wortmannin, or TPA and RAP. We found that IPC failed to induce tolerance in $t P A^{-/-}$neurons $(57.27 \% \pm 2.92 \%$ and $56.01 \% \pm 2.85 \%$ neuronal survival without and with preconditioning, respectively) indicating that endogenous tPA is needed for the induction of ischemic tolerance (Figure 7C). In contrast, we found that incubation of $t \mathrm{PA}^{-/-}$neurons with tPA during the preconditioning phase increased neuronal survival to $84.3 \% \pm 2.99 \%$, confirming that the lack of preconditioning observed in $t P A^{-/-}$neurons was indeed due to tPA deficiency. However, this rescue effect of tPA was abrogated by coincubation with either MK-801 (56.81\% $\pm 2.08 \%$ neuronal survival) or wortmannin $(57.62 \% \pm 1.97 \%$; Figure $7 \mathrm{C})$. Importantly, coincubation with RAP potentiated the rescue effect of tPA $(92.52 \% \pm 1.3 \%)$.
Effect of endogenous tPA on IPC in vivo. Then we investigated in vivo the effect of endogenous tPA in an animal model of IPC. First, we performed an in situ zymography assay in brain sections from WT and $t P A^{-/-}$mice $(n=4)$ immediately after 3 episodes of sublethal $\mathrm{BCCAO}$, performed as described in Methods (Figure 8A). We found that this form of preconditioning not only induced an increase in tPA activity in the hippocampal CA1 layer (Figure 8B) but also failed to produce cell death in the same hippocampal field 72 hours later (Figure 8D). We did not observe an increase in caseinolytic activity in the CA1 layer of $t \mathrm{PA}^{-/-}$mice, indicating that the proteolytic activity observed in the CA 1 layer of WT mice was due to tPA (Figure 8C). Likewise, as in WT mice, this paradigm of preconditioning did not induce cell death in $\mathrm{PP}^{-{ }^{-}}$animals (Figure $8 \mathrm{E}$ ). To study the effect of IPC on plasminogen expression in the CA1 layer, WT and $\mathrm{Plg}^{-1-}$ mice underwent 3 episodes of sub-lethal BCCAO, followed by immunohistochemical detection of plasminogen. Our results demonstrate that IPC increased the expression of plasminogen in the CA1 hippocampal layer (Figure 8, F and G). Importantly, we did not detect immunoreactivity in $\mathrm{Plg}^{-/-}$mice (data not shown). Then we used this model to investigate whether the increase in tPA activity in the CA1 layer induced by IPC has a protective effect against a subsequent lethal ischemic injury in the same hippocampal field. WT, $t \mathrm{PA}^{-/-}$, and $\mathrm{Plg}^{-/}$mice $(n=6)$ underwent IPC as described in Figure $8 \mathrm{~A}$, followed 30 minutes later by 20 minutes of BCCAO and analysis of hippocampal cell death 72 hours later. We found that 
A

Cerebral perfusion

$(\mathrm{AU})$

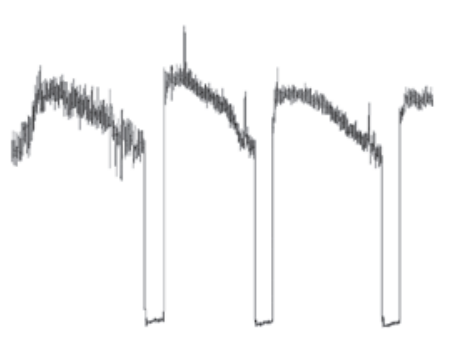

\section{B}

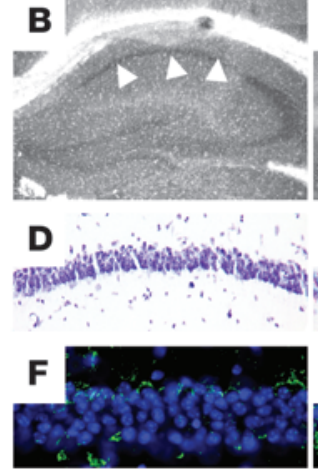

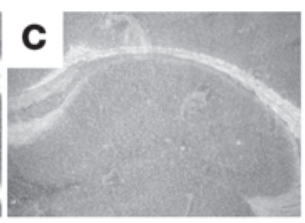

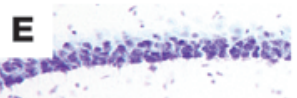

G
Figure 8

IPC increases tPA activity and plasminogen expression in the hippocampal CA1 layer. (A) Representative example of cerebral perfusion changes in the hippocampus during preconditioning with 3 episodes of BCCAO of 1-minute duration, each separated by 5-minute intervals of normal perfusion. (B and $\mathbf{C}$ ) Representative in situ zymography assay in WT and $t P A^{-/-}$mice immediately after 3 episodes of BCCAO performed as described in $\mathbf{A}$. Note the presence of tPA activity in the hippocampal CA1 layer (white arrows in $\mathbf{B}$ ). (D and E) Cresyl violet staining in the hippocampal CA1 layer of WT (D) and $t P A^{-/-}(\mathrm{E})$ mice 48 hours after 3 episodes of intermittent BCCAO. Note the absence of cell death despite a significant increase in tPA activity in the same hippocampal area as in WT mice. (F and $\mathbf{G})$ Immunoreactivity for plasminogen in the CA1 layer of WT mice before $(\mathbf{F})$ and after (G) IPC. Blue is DAPI, green is plasminogen. Original magnification, $\times 4$ (B and $\mathbf{C})$ and $\times 40$ (D-G). doses of KA (14). Our findings indicate that sublethal ischemia also increases tPA activity in the CA1 layer and that this effect is associated with neuronal survival. Together, these observations conflict with a proposed neurotoxic effect of tPA in the hippocampus.

A link between tPA and neurotoxicity has been controversial. Whereas some studies have demonstrated that tPA mediates neuronal death following a number of insults including the injection of KA into the hippocampus (9), alcohol withdrawal (29), stress (21), and focal cerebral ischemia (30), others have suggested that tPA is neuroprotective $(31,32)$. This apparent discrepancy of results may be explained not only by the differences intrinsic to the various experimental models, but also by the cell type studied in each case. Accordingly, we found that whereas tPA has a protective effect in hippocampal neurons, low concentrations of tPA are neurotoxic to cortical neurons. Likewise, whereas genetic deficiency of tPA does not have an effect on hypoxia-induced cell death in hippocampal neurons, $t P A^{-/-}$cortical neurons exhibit higher resistance to the hypoxic injury. Since its original description, it early IPC failed to induce tolerance against 20 minutes of BCCAO (data not shown). Then we decided to perform similar experiments in a model of delayed IPC. WT, $\mathrm{PA}^{-/-}$, and $\mathrm{Plg}^{-/-}$mice $(n=6)$ underwent IPC as described in Figure 8A, followed 24 hours later by 20 minutes of BCCAO. A subgroup of mice underwent 20 minutes of BCCAO without preconditioning. Seventy-two hours later, brains were harvested, and hippocampal cell death was studied in cresyl violet-stained sections as described in Methods. As shown in Figure 9, A, C, and E, 20 minutes of BCCAO induced extensive cell death in the hippocampal CA1 field of WT, $\mathrm{PA}^{-/-}$, and $\mathrm{Plg}^{-/-}$mice, and as previously described by others (15), IPC induced tolerance to the lethal ischemic insult in the CA1 layer of WT mice (Figure 9B). In contrast, the protective effect of IPC was abrogated in $t P A^{-/}$ and $\mathrm{Plg}^{-1}$ mice (Figure 9, D and F). Accordingly, IPC decreased the mean score of hippocampal damage in WT mice from $3.5 \pm 0.75$ to $1.55 \pm 0.527$ but did not have any effect in either $t P A^{-/-}(3.8 \pm 0.34$ without IPC and $3.7 \pm 0.36$ with IPC) or $\mathrm{Plg}^{-/-}$mice. (3.90 \pm 0.30 without IPC and $3.72 \pm 0.44$ with IPC; Figure 9G) Because our in vitro experiments demonstrated that the protective effect of tPA was mediated by Akt phosphorylation, we then performed Western blot analysis for pAkt in hippocampal extracts from WT, $t P A^{-/-}$, and $\mathrm{Plg}^{-/}$mice $0,1,6$, and 24 hours after IPC. Our results indicate that IPC induces an increase in pAkt expression in WT but not in $t \mathrm{PA}^{-/-}$or $\mathrm{Plg}^{-/-}$mice (Figure $9 \mathrm{H}$ ). Together with our observations in neuronal cultures, these data suggest that the protective effect of tPA is mediated by an Akt-induced gene.

\section{Discussion}

The work presented here indicates an association between lack of tPA activity and increased susceptibility to cell death in the CA1 layer. This hippocampal field is devoid of tPA activity under nonischemic conditions but has a high expression of $t P A$ mRNA (14). Indeed, tPA activity increases in CA1 hippocampal neurons following certain types of stimuli such as exposure to sublethal has been found that ischemic tolerance may be induced not only by sublethal ischemia but also by other types of events such as cortical spreading depression (33), brief episodes of seizures (34), and low doses of endotoxin (35). Importantly, these stimuli also increase tPA activity $(7,36)$, suggesting that induction of tPA activity is a basic endogenous neuroprotective response in the hippocampus.

Our results indicate that although endogenous tPA does not have an effect in early preconditioning, high concentrations of recombinant tPA induce early ischemic tolerance, and this effect is independent of tPA's proteolytic activity and requires the engagement of a member of the LDL receptor family. Nevertheless, we do not know whether such high concentrations of tPA can be reached in vivo in the synaptic space. The abrogation of the protective effect of tPA by RAP in early preconditioning suggests that the development of tPA-induced early tolerance is mediated by the interaction between tPA and a member of the LDL receptor family. Our findings that NMDAR antagonism fails to abrogate the early protective effect of tPA and that incubation with tPA at concentrations known to protect cells from a lethal hypoxic injury does not prevent KA-induced cell death indicate that the mechanism whereby tPA induces early tolerance is independent of the excitotoxic pathway.

In contrast, we found that low concentrations of tPA have a robust delayed preconditioning effect that requires tPA's proteolytic activity and plasminogen as its substrate. This agrees with recent reports indicating that plasminogen bound to cortical neurons is activated by tPA and that plasmin has a beneficial effect on neuronal survival (37). We found that in contrast to tPA-induced early preconditioning, the effect of tPA on delayed preconditioning is inhibited by NMDAR antagonists, and that TPA induces delayed tolerance against KA-induced neuronal death, indicating that tPAinduced delayed preconditioning is mediated by attenuation of the excitotoxic injury. Whereas our results conflict with previous observations by others showing that genetic deficiency of tPA pro- 

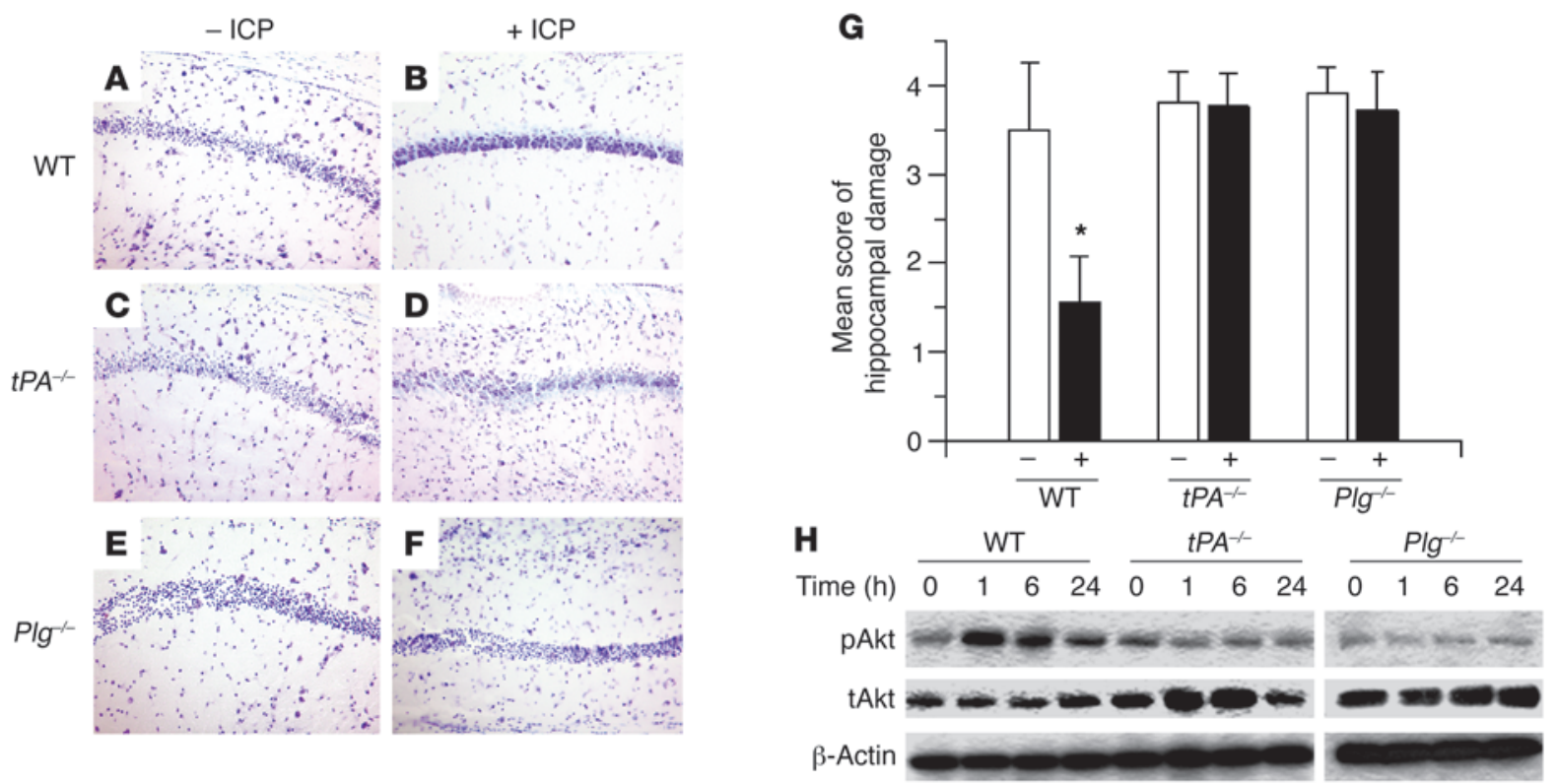

\section{Figure 9}

Effect of tPA deficiency in an in vivo model of delayed IPC. (A-F). Representative images of cresyl violet staining through the dorsal hippocampus of WT, $t P A^{-/}$, and $\mathrm{Plg}^{-/-}$mice 72 hours after 20 minutes of BCCAO without (- IPC) and with (+ IPC) IPC performed 24 hours earlier as described in Methods. Original magnification, $\times 20$. (G) Mean score of hippocampal damage in WT, $t P A^{-1-}$, and $P / g^{-1-}$ mice 72 hours after 20 minutes of BCCAO without (-) or with (+) IPC 24 hours earlier. $n=8-10$ observations. ${ }^{\star} P<0.05$ compared with preconditioned WT mice. (H) Representative Western blot analysis for Akt phosphorylated at serine 473 (pAkt) in WT, $t P A^{-/-}$, and Ig $^{-/-}$mice $0,1,6$, and 24 hours after IPC performed as described in Figure 8. Lanes were run on the same gel but were noncontiguous.

tects hippocampal neurons from the intracerebral injection of KA (9), they agree with other reports that indicate a protective effect of tPA against KA-induced neuronal death $(31,38)$. However, as our results also demonstrate, the effect of tPA on KA-induced cell death is highly dependent on the characteristics of the experimental paradigm. The observation that RAP potentiates the protective effect of tPA on delayed preconditioning suggests that blockade of the LDL receptor inhibits the uptake of tPA by a member of the LDL receptor family, increasing tPA's availability in the synaptic space to interact with plasminogen and the NMDAR.

In vivo experiments have shown that NR2A-containing NMDA receptors mediate the effect of IPC in the hippocampus $(26,27)$. Here we demonstrate that tPA and plasmin cleave the NR2A subunit of the NMDA receptor in hippocampal neurons and that both plasmin and NMDAR activation are needed for tPA's delayed protective effect. Based on these observations, we postulate a model whereby tPA released from hippocampal neurons in response to IPC catalyzes the conversion of plasminogen into plasmin, with plasmin-induced cleavage of the NR2A subunit and NMDAR activation. Unfortunately, the lack of selective inhibitors of the NR2A subunit $(39,40)$ does not allow us to characterize the involvement of this subunit in more detail.

A role for endogenous tPA in the development of ischemic tolerance is supported by our observation that $t P A^{-/-}$neurons fail to develop tolerance in response to a sublethal hypoxic insult and that this lack of effect is reversed by incubation with recombinant tPA. Additionally, inhibition of plasminogen/plasmin blocked the effect of hypoxic preconditioning in WT neurons. The importance of endogenous tPA for the induction of delayed ischemic tolerance is further confirmed by our observations in the vivo model of IPC indicating that compared with WT mice, sublethal BCCAO fails to induce tolerance in $\mathrm{tPA}^{-/-}$and $\mathrm{Plg}^{-/-}$mice.

Activation of Akt occurs through its phosphorylation (pAkt), which is dependent upon the signaling pathways of PI3K. The expression of pAkt increases dramatically in neurons during cellular stress or injury, where it has been associated with activation of antiapoptotic pathways $(41,42)$. Several lines of evidence indicate that pAkt plays a pivotal role in hypoxic/ischemic preconditioning (43). Our data show that tPA induces a rapid phosphorylation of Akt in neurons and that this effect requires tPA's proteolytic activity and engagement of the NMDAR. Importantly, treatment with wortmannin not only abrogated the effect of tPA on delayed preconditioning, but also inhibited the development of delayed hypoxic tolerance, suggesting that the expression of Akt-regulated genes is required for the delayed protective effect of tPA. The importance of tPA and Akt in the development of ischemic tolerance is further supported by our in vivo observation that IPC induces a rapid increase in hippocampal pAkt expression and that this effect is attenuated in $\mathrm{PPA}^{-/-}$and $\mathrm{Plg}^{-/-}$mice. Our data show that whereas the immediate neuroprotective effect of tPA is independent of the phosphorylation of Akt, tPA-induced delayed ischemic tolerance occurs via NMDAR-mediated Akt phosphorylation.

Based on our observations we propose two models for the neuroprotective effect of $\mathrm{tPA}$ in the hippocampus. In the first, subtle changes in the microenvironment induce the release of neuronal tPA into the synaptic space, which then interacts with plasminogen on the cell surface, leading to plasmin-induced, NMDAR-mediated Akt phosphorylation. In the second, an acute injury induces a rapid and sustained increase in tPA activity in the extracellular space, leading to the activation of a cell signaling event mediated by a member of the 
LDL receptor family that results in neuroprotection. Both mechanisms of neuroprotection have important clinical implications not only for the prevention of hippocampal cell death, but also for the development of an effective neuroprotective strategy for clinical use.

\section{Methods}

Animals and reagents. Murine strains were male WT C57BL/6J, tPA-deficient $\left(t P A^{-/-}\right)$, and plasminogen-deficient $\left(\mathrm{Plg}^{-/}\right)$mice, 8-12 weeks old, backcrossed at least 7 generations into C57BL/6J mice, and their WT C57BL/6J controls. Experiments were approved by the Institutional Animal Care and Use Committee of Emory University. Recombinant murine tPA, itPA with an alanine-for-serine substitution at the active site Ser481 (S481A), human Glu plasminogen and Lys plasmin were purchased from Molecular Innovations. Other reagents were human $\alpha_{2}$-antiplasmin (Research Biomedical International), aprotinin (Calbiochem), EACA (MP Biomedicals), KA (Tocris Bioscience), the PI3K/Akt inhibitor wortmannin (Sigma-Aldrich), RAP (provided by Dudley K. Strickland, University of Maryland, Baltimore, Maryland, USA), and the NMDAR antagonists MK-801 (Tocris Bioscience) and DL-AP5 (Ascent Scientific).

Animal model of delayed neuronal death, IPC, and histological analysis of hippocampalinjury. Mice were anesthetized with $4 \%$ chloral hydrate $(400 \mathrm{mg} / \mathrm{kg}$ intraperitoneally) and then subjected to BCCAO for 20 minutes. Cerebral perfusion in the forebrain was monitored with a laser Doppler (Perimed), and only animals with a greater than $85 \%$ decrease in cerebral perfusion after occlusion and complete recovery after the withdrawal of the microclips were included in this study. Three or 5 days later, mice were transcardially perfused, and brains were cut into $20-\mu \mathrm{m}$ sections through the dorsal and ventral hippocampus and stained with cresyl violet, DAPI (Anaspec), Fluoro-Jade (Histo-Chem Inc.), and TUNEL (Calbiochem), following the manufacturer's instructions. Each observation was repeated 6 times. For IPC, both carotid arteries were exposed and clipped 3 times during 1 minute with 5-minute intervals of reperfusion in between. Twenty-four hours later, animals were re-anesthetized, and both carotid arteries were clipped during 20 minutes. A subgroup of mice underwent 20 minutes of BCCAO without preconditioning. Three days later brains were harvested, and $20-\mu \mathrm{m}$ sections through the hippocampus were stained with cresyl violet. Neuronal damage was qualitatively determined with a scoring system described by Murakami et al. (44): grade 0 , no damage to any hippocampal subregion; grade 1 , scattered neuronal death in the CA1 region; grade 2, moderate neuronal death in the CA1 region; grade 3, complete neuronal death in the CA1 region; and grade 4 , extensive cell death in other hippocampal regions. Each observation was repeated 15 times. A group of WT and $\mathrm{Plg}^{-1-}$ brains $(n=4)$ were harvested 30 minutes after either IPC or sham surgery and stained with an affinity-purified rabbit anti-mouse plasminogen (Molecular Innovations).

In situ zymography assay. In situ zymography assays were performed as described elsewhere (13). Briefly, following 20 minutes of BCCAO or 3 episodes of 1 minute of BCCAO separated by 5 minutes of reperfusion, WT and $t P A^{-/-}$brains were cut into $20-\mu \mathrm{m}$ sections and overlaid with a mixture of $0.5 \mathrm{ml} \%$ nonfat dry milk, $0.75 \mathrm{ml}$ PBS, $0.7 \mathrm{ml}$ of a $2.5 \%$ agar solution in water, and plasminogen at a final concentration of $30 \mu \mathrm{g} / \mathrm{ml}$. Slides were incubated at $37^{\circ} \mathrm{C}$ in a humid chamber, and zymograms were allowed to develop for 2-6 hours. Identical experiments were carried out with overlay without plasminogen. Each observation was repeated 4 times. Pictures were taken in a dark field microscope with a $\times 4$ magnification.

Hippocampal neuronal cultures and determination of neuronal survival. Hippocampal and cortical neurons were cultured from E19 WT and $t P A^{-1}$ mice as described elsewhere (23). To study the effect of hypoxia on neuronal death, neurons were exposed in an anaerobic chamber (Don Whitley Scientific) to OGD conditions ( $<0.1 \%$ oxygen) for $0-60$ minutes, followed 24 hours later by determination of cell death by the MTT assay (ATCC), a LIVE/DEAD
Viability/Cytotoxicity assay (Molecular Probes), and the Trypan blue viability assay (Thermo Scientific), following the manufacturer's instructions. The number of dead cells was expressed as a percentage over the total number of cells in each field at $\times 40$ magnification in 4 different fields in 4 separate coverslips. For the MTT assay, results are expressed as a percentage of cell survival observed in control cells maintained under normoxic conditions. Each experiment was performed in cultures from 3 different animals, and each observation was repeated 6 times. A subgroup of neurons was incubated under normoxic conditions with progressive $0-1 \mu \mathrm{M}$ concentrations of tPA, followed 24 hours later by determination of cell survival by the MTT assay. Each observation was repeated in cultures from 3 different animals $(n=10)$.

Early and delayed preconditioning with $t P A$. For early and delayed preconditioning, we used hippocampal neurons at 10 days in vitro. For early preconditioning, cells were exposed to OGD conditions for 55 minutes and simultaneously incubated with $0-1 \mu \mathrm{M}$ active tPA, $1 \mu \mathrm{M}$ itPA, or a combination

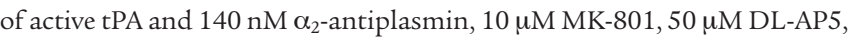
or $100 \mathrm{nM}$ RAP. A subgroup of neurons was incubated with $100 \mathrm{nM}$ plasmin alone. A subset of neurons was incubated under normoxic conditions with $1 \mu \mathrm{M}$ tPA and $250 \mu \mathrm{M} \mathrm{KA}$. A third group of neurons was treated with $20 \mathrm{nM}$ wortmannin either alone or in combination with $60 \mathrm{nM} \mathrm{tPA}$. Twenty-four hours later, cell survival was determined with the MTT assay. Each observation was repeated 20 times with neurons cultured from 3 different animals. For delayed preconditioning, neurons were incubated under normoxic conditions with $0-1 \mu \mathrm{M}$ active tPA, $1 \mu \mathrm{M}$ itPA, or a combination of active tPA and $140 \mathrm{nM} \alpha_{2}$-antiplasmin, $1.4 \mu \mathrm{M}$ aprotinin, $20 \mathrm{mM}$ EACA, $10 \mu \mathrm{M}$ MK-801, $50 \mu \mathrm{M}$ DL-AP5, or $100 \mathrm{nM}$ RAP. A subgroup of neurons was incubated with either $100 \mathrm{nM}$ plasmin or $200 \mathrm{nM}$ plasminogen alone. A second subgroup of neurons was treated with $20 \mathrm{nM}$ wortmannin either alone or in combination with $60 \mathrm{nM}$ tPA or $100 \mathrm{nM}$ plasmin. Twenty-four hours later, cells were exposed to OGD conditions for 55 minutes. A subgroup of neurons was incubated with active tPA and treated 24 hours later with $250 \mu \mathrm{M} \mathrm{KA}$ under normoxic conditions. Twenty-four hours later, cell survival was determined in all groups with the MTT assay. Each experiment was repeated with neurons cultured from 3 different animals, and each observation was repeated 15-20 times.

Hypoxic preconditioning. WT and $t P A^{-/-}$neurons were exposed to OGD conditions for 30 minutes (preconditioning), followed 24 hours later by incubation under OGD conditions for 55 minutes and determination of cell survival 24 hours later. A subgroup of cells was incubated under OGD conditions 55 minutes without preconditioning. A subset of WT cells was incubated during the preconditioning phase with $140 \mathrm{nM} \alpha_{2}$-antiplasmin, 1.4 $\mu \mathrm{M}$ aprotinin, $20 \mathrm{mM}$ EACA, $10 \mu \mathrm{M}$ MK-801, $50 \mu \mathrm{M}$ DL-AP5, $100 \mathrm{nM}$ $\mathrm{RAP}$, or $20 \mathrm{nM}$ wortmannin. A subgroup of $t P A^{-/-}$neurons was incubated during the preconditioning phase with $60 \mathrm{nM} \mathrm{tPA}$ or $100 \mathrm{nM}$ plasmin or with a combination of tPA and plasmin; tPA and $20 \mathrm{nM}$ wortmannin; or tPA and $10 \mu \mathrm{M}$ MK-801, $50 \mu \mathrm{M}$ DL-AP5, or $100 \mathrm{nM}$ RAP. Twenty-four hours after exposure to 55 minutes of OGD, cell survival was quantified with the MTT assay. Each observation was repeated 10-15 times.

TPA activity assay. TPA activity was determined in the media of hippocampal and cortical neurons exposed to OGD conditions for 0-60 minutes using an ELISA kit from Molecular Innovations and following the manufacturer's instructions. Each experiment was performed with cultures from 3 different animals, and each observation was repeated 6 times in each culture.

Western blot analysis. WT hippocampal neurons were incubated for 30 minutes with $100 \mathrm{nM}$ tPA, $100 \mathrm{nM}$ itPA, or a combination of tPA and $10 \mu \mathrm{M} \mathrm{MK}-801$. WT and $t P A^{-/-}$hippocampal neurons were exposed to OGD conditions for 30 minutes. WT and $t P A^{-/-}$mice underwent IPC with 3 episodes of transient $\mathrm{BCCAO}$ as described above, and brains were harvested 1, 6, and 24 hours later. A subgroup of sham-operated WT and $t P A^{-/-}$mice was used as controls. After chemical, hypoxic, or IPC, cells and 
hippocampal brain extracts were homogenized, followed by loading of $16 \mu \mathrm{g}$ of total protein for SDS-PAGE electrophoresis and immunoblotting with antibodies directed against Akt phosphorylated at serine 473 (1:1,000; Cell Signaling Technology), total Akt (Cell Signaling Technology), or $\beta$-actin (Sigma-Aldrich). To study the expression of the NR2A subunit of the NMDAR, WT hippocampal neurons were incubated with $60 \mathrm{nM}$ tPA or $100 \mathrm{nM}$ plasmin for 60 minutes, followed by Western blot analysis as described above with an anti-NR2A antibody at 1:1,000 dilution (Millipore catalog 07-632). Each observation was repeated 3 times.

Statistics. Values are expressed as percentage or mean \pm SD when appropriate. Statistical analysis was performed with the $t$ test followed by the Wilcoxon signed-ranked test. $P$ values of less than 0.05 were considered significant.

\section{Acknowledgments}

This work was supported in part by NIH grants NS-062073 and HL-095063 (to M. Yepes).

Received for publication November 10, 2009, and accepted in revised form March 10, 2010.

Address correspondence to: Manuel Yepes, Department of Neurology and Center for Neurodegenerative Disease, Whitehead Biomedical Research Building, 615 Michael Street, Suite 505J, Atlanta, Georgia 30322, USA. Phone: 404.712.8358; Fax: 404.727.3728; E-mail: myepes@emory.edu.
1. Bugge TH, Kombrinck KW, Flick MJ, Daugherty CC, Danton MJ, Degen JL. Loss of fibrinogen rescues mice from the pleiotropic effects of plasminogen deficiency. Cell. 1996;87(4):709-719.

2. Nassar $T$, et al. In vitro and in vivo effects of tPA and PAI-1 on blood vessel tone. Blood. 2004; 103(3):897-902.

3. Polavarapu R, et al. Tissue-type plasminogen activator-mediated shedding of astrocytic low-density lipoprotein receptor-related protein increases the permeability of the neurovascular unit. Blood. 2007;109(8):3270-3278.

4. Yepes M, Sandkvist M, Moore EG, Bugge TH, Strickland DK, Lawrence DA. Tissue-type plasminogen activator induces opening of the blood-brain barrier via the LDL receptor-related protein. J Clin Invest. 2003;112(10):1533-1540.

5. Qian Z, Gilbert ME, Colicos MA, Kandel ER, Kuhl D. Tissue-plasminogen activator is induced as an immediate-early gene during seizure, kindling and long-term potentiation. Nature. 1993;361(6411):453-457.

6. Seeds NW, Williams BL, Bickford PC. Tissue plasminogen activator induction in Purkinje neurons after cerebellar motor learning. Science. 1995;270(5244):1992-1994.

7. Yepes M, et al. Regulation of seizure spreading by neuroserpin and tissue-type plasminogen activator is plasminogen-independent. J Clin Invest. 2002;109(12):1571-1578.

8. Mataga N, Nagai N, Hensch TK. Permissive proteolytic activity for visual cortical plasticity. Proc Natl Acad Sci U S A. 2002;99(11):7717-7721.

9. Tsirka SE, Gualandris A, Amaral DG, Strickland S. Excitotoxin-induced neuronal degeneration and seizure are mediated by tissue plasminogen activator. Nature. 1995;377(6547):340-344.

10. Yepes $M$, et al. Neuroserpin reduces cerebral infarct volume and protects neurons from ischemiainduced apoptosis. Blood. 2000;96(2):569-576.

11. Bingman VP. The importance of comparative studies and ecological validity for understanding hippocampal structure and cognitive function. Hippocampus. 1992;2(3):213-219.

12. Wilde GJ, Pringle AK, Wright P, Iannotti F. Differential vulnerability of the CA1 and CA 3 subfields of the hippocampus to superoxide and hydroxyl radicals in vitro. J Neurochem. 1997;69(2):883-886.

13. Sappino AP, et al. Extracellular proteolysis in the adult murine brain. J Clin Invest. 1993;92(2):679-685.

14. Salles FJ, Strickland S. Localization and regulation of the tissue plasminogen activator-plasmin system in the hippocampus. J Neurosci. 2002;22(6):2125-2134.

15. Kitagawa K, et al. 'Ischemic tolerance' phenomenon detected in various brain regions. Brain Res. 1991;561(2):203-211.

16. Matsushima K, Hakim AM. Transient forebrain ischemia protects against subsequent focal cere- bral ischemia without changing cerebral perfusion. Stroke. 1995;26(6):1047-1052.

17. Grabb MC, Choi DW. Ischemic tolerance in murine cortical cell culture: critical role for NMDA receptors. J Neurosci. 1999;19(5):1657-1662.

18. Soriano FX, Papadia S, Hofmann F, Hardingham NR, Bading H, Hardingham GE. Preconditioning doses of NMDA promote neuroprotection by enhancing neuronal excitability. $J$ Neurosci. 2006;26(17):4509-4518.

19 . Nicole O, et al. The proteolytic activity of tissueplasminogen activator enhances NMDA receptormediated signaling. Nat Med. 2001;7(1):59-64.

20 . Samson AL, et al. Tissue-type plasminogen activator requires a co-receptor to enhance NMDA receptor function. J Neurochem. 2008;107(4):1091-1101.

21. Pawlak R, Magarinos AM, Melchor J, McEwen B, Strickland S. Tissue plasminogen activator in the amygdala is critical for stress-induced anxiety-like behavior. Nat Neurosci. 2003;6(2):168-174.

22. Samson AL, Medcalf RL. Tissue-type plasminogen activator: a multifaceted modulator of neurotransmission and synaptic plasticity. Neuron. 2006;50(5):673-678.

23. Zhang X, Polavarapu R, She H, Mao Z, Yepes M. Tissue-type plasminogen activator and the low-density lipoprotein receptor-related protein mediate cerebral ischemia-induced nuclear factor-kappaB pathway activation. Am J Pathol. 2007;171(4):1281-1290.

24. Zhang C, An J, Strickland DK, Yepes M. The lowdensity lipoprotein receptor-related protein 1 mediates tissue-type plasminogen activator-induced microglial activation in the ischemic brain. $A m J$ Pathol. 2009;174(2):586-594.

25. Liot G, et al. 2,7-Bis-(4-amidinobenzylidene)-cycloheptan-1-one dihydrochloride, tPA stop, prevents tPA-enhanced excitotoxicity both in vitro and in vivo. J Cereb Blood Flow Metab. 2004;24(10):1153-1159.

26. Chen M, et al. Differential roles of NMDA receptor subtypes in ischemic neuronal cell death and ischemic tolerance. Stroke. 2008;39(11):3042-3048.

27. Liu Y, et al. NMDA receptor subunits have differential roles in mediating excitotoxic neuronal death both in vitro and in vivo. $J$ Neurosci. 2007;27(11):2846-2857.

28. Yuan $\mathrm{H}$, et al. The serine protease plasmin cleaves the amino-terminal domain of the NR2A subunit to relieve zinc inhibition of the $\mathrm{N}$-methyl-D-aspartate receptors. J Biol Chem. 2009;284(19):12862-12873.

29. Skrzypiec AE, Maiya R, Chen Z, Pawlak R, Strickland S. Plasmin-mediated degradation of laminin gamma-1 is critical for ethanol-induced neurodegeneration. Biol Psychiatry. 2009;66(8):785-794.

30. Wang YF, Tsirka SE, Strickland S, Stieg PE, Soriano $\mathrm{SG}$, Lipton SA. Tissue plasminogen activator (tPA) increases neuronal damage after focal cerebral ischemia in wild-type and tPA-deficient mice. Nat Med. 1998;4(2):228-231.

31. Kim YH, Park JH, Hong SH, Koh JY. Nonpro- teolytic neuroprotection by human recombinant tissue plasminogen activator. Science. 1999;284(5414):647-650.

32. Liot $G$, et al. Tissue-type plasminogen activator rescues neurones from serum deprivationinduced apoptosis through a mechanism independent of its proteolytic activity. J Neurochem. 2006;98(5):1458-1464.

33. Kobayashi S, Harris VA, Welsh FA. Spreading depression induces tolerance of cortical neurons to ischemia in rat brain. J Cereb Blood Flow Metab. 1995;15(5):721-727.

34. Kapinya KJ, et al. Tolerance against ischemic neuronal injury can be induced by volatile anesthetics and is inducible NO synthase dependent. Stroke. 2002;33(7):1889-1898.

35. Tasaki K, Ruetzler CA, Ohtsuki T, Martin D, Nawashiro H, Hallenbeck JM. Lipopolysaccharide pre-treatment induces resistance against subsequent focal cerebral ischemic damage in spontaneously hypertensive rats. Brain Res. 1997; 748(1-2):267-270.

36. Calabresi $\mathrm{P}$, et al. Tissue plasminogen activator controls multiple forms of synaptic plasticity and memory. Eur J Neurosci. 2000;12(3):1002-1012.

37. Ho-Tin-Noe B, Enslen H, Doeuvre L, Corsi JM, Lijnen HR, Angles-Cano E. Role of plasminogen activation in neuronal organization and survival. Mol Cell Neurosci. 2009;42(4):288-295.

38. Flavin MP, Zhao G. Tissue plasminogen activator protects hippocampal neurons from oxygen-glucose deprivation injury. J Neurosci Res. 2001;63(5):388-394.

39. Neyton J, Paoletti P. Relating NMDA receptor function to receptor subunit composition: limitations of the pharmacological approach. J Neurosci. 2006;26(5):1331-1333.

40. Frizelle PA, Chen PE, Wyllie DJ. Equilibrium constants for (R)-[(S)-1-(4-bromo-phenyl)-ethylamino]-(2,3-dioxo-1,2,3,4-tetrahydroquino xalin5-yl)-methyl]-phosphonic acid (NVP-AAM077) acting at recombinant NR1/NR2A and NR1/NR2B $\mathrm{N}$-methyl-D-aspartate receptors: implications for studies of synaptic transmission. Mol Pharmacol. 2006;70(3):1022-1032.

41. Datta SR, Brunet A, Greenberg ME. Cellular survival: a play in three Akts. Genes Dev. 1999;13(22):2905-2927.

42. Dudek H, et al. Regulation of neuronal survival by the serine-threonine protein kinase Akt. Science. 1997;275(5300):661-665.

43. Yano S, et al. Activation of Akt/protein kinase B contributes to induction of ischemic tolerance in the CA1 subfield of gerbil hippocampus. J Cereb Blood Flow Metab. 2001;21(4):351-360.

44. Murakami K, Kondo T, Epstein CJ, Chan PH. Overexpression of CuZn-superoxide dismutase reduces hippocampal injury after global ischemia in transgenic mice. Stroke. 1997;28(9):1797-1804. 